\title{
A Phase II Study of Antineoplastons A10 and AS2-1 in Children with Brain Tumors. Final Report (Protocol BT-10)
}

\author{
Stanislaw R. Burzynski, Tomasz J. Janicki, Gregory S. Burzynski, Ania Marszalek \\ Burzynski Clinic, Houston, TX, USA \\ Email: gsb@burzynskiclinic.com
}

How to cite this paper: Burzynski, S.R., Janicki, T.J., Burzynski, G.S. and Marszalek, A. (2017) A Phase II Study of Antineoplastons A10 and AS2-1 in Children with Brain Tumors. Final Report (Protocol BT-10). Journal of Cancer Therapy, 8, 173-187. https://doi.org/10.4236/jct.2017.82015

Received: January 19, 2017

Accepted: February 13, 2017

Published: February 16, 2017

Copyright $\odot 2017$ by authors and Scientific Research Publishing Inc. This work is licensed under the Creative Commons Attribution International License (CC BY 4.0).

http://creativecommons.org/licenses/by/4.0/

(c) (i) Open Access

\begin{abstract}
Despite dramatic progress over the last 50 years in the treatment of many childhood cancers, primary brain tumors remain the leading cause of death in pediatric oncology. This phase II study evaluated the efficacy and safety of Antineoplastons A10 and AS2-1 given in combination (ANP). Thirty-four patients, with a median age of 10.4 years, were enrolled in the study. Thirty- two patients (94.1\%), were Caucasians while 21 (61.8\%) were female and 13 were male (38.2\%). Twenty-four patients (70.6\%) suffered from a brainstem glioma (BSG) or high-grade tumor. Ten patients $(29.4 \%)$ suffered from a low-grade tumor. A distinct sub-group of three patients with low grade tumors had a ganglioglioma (GG). Eighty-two percent of patients had failed standard treatment. Daily ANP was administered by IV infusion, every four hours, until an objective response (OR) was documented, and then for an additional eight months. The median doses of A10 and AS2-1 were 11.64 $\mathrm{g} / \mathrm{kg} / \mathrm{d}$ and $0.45 \mathrm{~g} / \mathrm{kg} / \mathrm{d}$, respectively. A complete response (CR) was documented in two patients (5.9\%), a partial response (PR) in four patients $(11.8 \%)$, and stable disease (SD) in six patients (17.6\%). Objective responses were observed in diffuse intrinsic pontine glioma (DIPG), thalamic pilocytic astrocytoma with brainstem involvement, ganglioglioma and pilocytic astrocytoma. Six-month progression-free survival (PFS) was $35.3 \%$. Overall survival (OS) at two and five years was $37.6 \%$ and $34.5 \%$, respectively. Two patients experienced grade 4 hypernatremia while three experienced grade 3 hypokalemia. In this group of patients, ANP showed good efficacy and an acceptable toxicity profile.
\end{abstract}

\section{Keywords}

Antineoplastons A10 and AS2-1, Brainstem Glioma, DIPG, Ganglioglioma, Recurrent Glioma 


\section{Introduction}

In the last 50 years, there has been dramatic progress in the treatment of most childhood cancers, which has translated into an improvement in long-term overall survival (OS) for $80 \%$ of these patents [1]. Unfortunately, tumors of the central nervous system (CNS) remain the leading cause of death in pediatric oncology [1] [2]. Childhood brain tumors are a diverse group of neoplasms which can be subdivided into 12 main categories [1]. The largest group, gliomas, accounts for $53 \%$ of tumors in children ages $0-14$ years and $37 \%$ of tumors in adolescents, age 15 - 19 years [1]. Low-grade astrocytomas (LGA) are the most common type of gliomas. LGA grade 1 (pilocytic) has a relatively favorable prognosis, but the pilomyxoid variant is more likely to disseminate and has a more aggressive course [3]. Multicentric tumors are not curable by currently available treatments. High-grade gliomas (HGG) and diffuse intrinsic pontine glioma (DIPG) are less common, but remain incurable and continue to provide significant challenges for pediatric oncologists [4]. Antineoplastons A10 and AS2-1 are synthetic amino acid derivatives utilized in combination (ANP). A10 consists of a 4:1 ratio of phenylacetylglutaminate sodium (PG) and phenylacetylisoglutaminate sodium (isoPG). AS2-1 consists of a 4:1 ratio of phenylacetate sodium (PN and PG) [5] [6]. Initial clinical responses in the treatment of pediatric brain tumors led to the design and implementation of a series of clinical studies to evaluate the safety and efficacy of ANP [7]. The first study, conducted according to Protocol BT-06 assessed the efficacy and safety of ANP in children diagnosed with recurrent (persistent) HGG [8]. This paper discusses the results of a second study conducted according to Protocol BT-10, which was designed to provide a preliminary evaluation of the results of ANP therapy in newly-diagnosed and recurrent high-grade and low-grade pediatric brain tumors. Subsequent studies concentrated on different subgroups of pediatric brain tumors including brainstem glioma (BSG), LGA, optic pathway glioma (OPG), recurrent primitive neuroectodermal tumor (PNET), atypical teratoid/rhabdoid tumor (AT/RT), ependymoma, choroid plexus carcinoma, and craniopharyngioma (CP) [9]-[17]. The interim results on some of these trials have been published [6]-[17].

\section{Patients and Methods}

\subsection{Patient Population}

Enrolled patients were more than 6 months, but less than 18 years of age, with radiologic evidence of recurrent, refractory, progressive or persistent primary brain tumors despite receiving standard therapy. Radiologic evidence of tumor location and size was obtained via magnetic resonance imaging (MRI) performed within 14 days of starting ANP.

Inclusion criteria included a histologically confirmed, primary malignant brain tumor considered to be incurable following standard therapy. Patients were at least 1) four weeks past any surgical therapy, having made a complete recovery; 2) eight weeks past the last dose of radiation therapy (RT); and 3) four 
weeks past the last dose of chemotherapy (six weeks for nitrosoureas) or immunotherapy. However, patients with clear evidence of disease progression during initial therapy could be enrolled earlier if the investigator had determined that it is safe to administer ANP to such patients. Exclusion criteria included active serious active infections, fever or other medical conditions that would interfere with the evaluation of ANP (i.e., severe heart or lung disease or hepatic failure) Patients with uncontrolled hypertension, a history of congestive heart failure or a history of renal disease were also excluded.

It is generally accepted that the diagnosis of BSG can be made by MRI without the necessity of a biopsy. In this way, DIPG can be diagnosed if the tumor has an epicenter in the pons and involves more than $50 \%$ of the pons (patients with neurofibromatosis are not included). Tumors that involve less than $50 \%$ of the pons or are exophytic in nature were classified as DIPG if they had anaplastic, glioblastoma (GBM) or gliosarcoma (GS) histology [18] [19] [20] [21]. Other types of BSG include focal, exophytic, cervicomedullary and midbrain tumors [22] [23].

All study patients and/or their legal guardians read, understood, and signed written Informed Consent Documents prior to enrollment. This study was conducted in accordance with the US Code of Federal Regulations, Title 21, Parts 11, 50, 56, and 312; the Declaration of Helsinki (1964) including all amendments and revisions; the Good Clinical Practices: Consolidated Guideline (E6); International Conference on Harmonization; and the FDA's Guidance for Industry. The study was sponsored by the BRI and conducted by the Burzynski Clinic (BC) in Houston, Texas. Patients received ANP free-of-charge.

\subsection{Study Design}

The study was designed as a single-arm (i.e., no placebo group), two-stage, interventional Phase II trial of ANP as monotherapy in a high-risk, poor-prognosis study population [24]. The study was listed by the National Cancer Institute (NCI), performed under the supervision of an independent Institutional Review Board, the BRI-IRB, and conducted according to Protocol BT-10, which was submitted to the FDA under IND \# 43,742. Study enrollment commenced on 9/16/1996 and continued until 7/19/2012. The protocol was amended on occasion by BRI, but none of the amendments altered the study objectives/outcomes or affected patient safety.

\subsection{Statistical Considerations}

The primary endpoint was objective response to ANP, (i.e., complete response (CR) or partial response (PR)). Secondary endpoints included overall survival (OS) and progression-free survival (PFS). OS was measured from the first day of ANP administration until death from any cause. PFS was measured from the first day of ANP administration until the date of first observation of progressive disease (PD) or until death from any cause. The distributions of OS and PFS were estimated by a Kaplan-Meier analysis. 
The sample size was calculated based upon the method described by Chang et al. [24]. In this two-stage study, an interim analysis was conducted after 20 patients had been enrolled. Since one or more patients had achieved an objective radiographic response, an additional twenty patients could be recruited. An objective response rate to ANP of $\geq 10 \%$ (i.e., four objective responses) was considered "of interest" and sufficient to warrant further study. Because six objective responses were observed after the enrollment of 34 patients, the study was terminated early.

\subsection{Treatment}

Every four hours, ANP were administered through a dual channel infusion pump and subclavian vein catheter. The details of ANP therapy have previously been described [11].

Medications that were considered necessary for the patients' welfare and that did not interfere with the evaluation of ANP were given at the discretion of the investigator. The use of corticosteroids was carefully monitored. Patients received full supportive care when appropriate. Treatment with other antineoplastic or immunomodulatory agents was not permitted.

The initial three weeks of therapy were administered by BC staff on an outpatient basis, in Houston, Texas. Patients and/or their legal guardians were trained by clinic staff to self-administer ANP during this time. Beginning at week 4, ANP therapy was administered at home with 24-hour support from the clinic. At-home therapy and monitoring of the subject's condition were carried out under the supervision of the subject's local physician.

\subsection{Evaluation and Follow-Up}

Within 14 days of the start of ANP, a gadolinium-enhanced MRI measured all contrast-enhancing lesions. The products of the two greatest perpendicular diameters of all lesions were calculated and totaled, providing a baseline evaluation ("sum") for each study subject. While tumor measurements were based on the contrast enhanced lesions, tumor size was also measured utilizing T2 and FLAIR images [21] [25]. The details of the required laboratory tests and follow-up studies have previously been published [11]. Adverse events (AEs) were graded according to the Common Terminology Criteria for Adverse Events (CTCAE v.3.0). Pharmacokinetic studies have been carried out in earlier Phase I and other Phase II studies and were not included in the study. Based on these earlier studies there was no expectation of interference with ANP activity by ancillary medications, especially anti-seizure drugs.

\section{Results}

\subsection{Patient Demographics}

Patient enrollment began 9/16/1996 and continued until 7/19/2012. As of 2/17/2015, all patients had been removed from ANP therapy due to a CR, PD, a worsening clinical condition, or subject/legal guardian request. 
Thirty-four patients, with a median age of 10.4 years, were enrolled in the study. Thirty-two patients (94.1\%), were Caucasians while 21 (61.8\%) were female and 13 were male (38.2\%).

Eleven patients (32.4\%) suffered from BSG, of which nine (26.5\%) had a DIPG. Thirteen patients (38.2\%) suffered from high-grade tumors group, including five GBM and five anaplastic gliomas (AG), one gliosarcoma (GS), one primitive neuroectodermal tumor (PNET-medulloblastoma) and one supratentorial medulloepithelioma (sPNET).

The low-grade tumor group included ten patients. Three patients suffered from a ganglioglioma (GG) while seven patients suffered from other low-grade tumors, including astrocytoma, pilocytic astrocytoma, oligodendroglioma, optic pathway glioma (OPG), neurocytoma and craniopharyngioma.

There were three cases with leptomeningeal involvement and/or disseminated, multicentric tumors (astrocytoma, pilocytic astrocytoma and ganglioglioma) and one case of a multicentric OPG. Table 1 describes the patient characteristics.

\subsection{Treatment}

The median dosage of A10 was $11.64 \mathrm{~g} / \mathrm{kg} / \mathrm{d}$ (range, $2.89-19.26 \mathrm{~g} / \mathrm{kg} / \mathrm{d}$ ) while for AS2-1 it was $0.36 \mathrm{~g} / \mathrm{kg} / \mathrm{d}$ (range, $0.16-0.57 \mathrm{~g} / \mathrm{kg} / \mathrm{d}$ ). The duration of ANP therapy ranged from 0.2 to 46.6 months with a median of 3.1 months.

The median maximum effective daily dose of A10 in patients with an OR (calculated at the first MRI showing an OR) was $13.92 \mathrm{~g} / \mathrm{kg} / \mathrm{d}$ (range, 6.23 to $21.02 \mathrm{~g} / \mathrm{kg} / \mathrm{d}$ ) while the median time to an OR (six patients) was 4.7 months of ANP (range, 1.3 - 7.8 months).

\subsection{Response and Survival}

Responses to treatment and survival are summarized in Table 2, which describes the data for all patients as well as for particular subgroups. Six patients obtained an OR (17.6\%). There were two CRs (5.9\%) and four PRs (11.8\%). An additional six patients $(17.6 \%)$ had stable disease (SD) while 18 patients developed PD (52.9\%). Four patients (11.8\%) were not evaluable because they elected to discontinue ANP prematurely without having a follow-up MRI to evaluate their response to ANP.

In the DIPG group $(n=9)$ one patient achieved a CR $(11.1 \%)$, one achieved a PR (11.1\%), one patient had SD (11.1\%), and four patients developed PD (44.4\%). In the other two patients with a BSG, midbrain one patient achieved a CR (50.0\%) and one patient developed PD (50.0\%).

In the LG group, two GG patients obtained a PR and one pilocytic astrocytoma patient obtained a PR.

In summary, all ORs occurred in the BSG and LG patient groups. In the BSG group, two of the nine patients with DIPG developed an OR; there was one CR and one PR. Both patients subsequently passed away. The patient who achieved a PR did not show signs of tumor progression and most likely died from an intratumoral hemorrhage. Of the two patients with a BSG, midbrain, one achieved 
Table 1. Patient Characteristics.

\begin{tabular}{|c|c|c|c|c|}
\hline & \multicolumn{4}{|c|}{$\begin{array}{l}\text { Enrolled Patients } \\
\qquad \mathrm{N}(\%)\end{array}$} \\
\hline & $\begin{array}{l}\text { All patients } \\
\quad \mathrm{N}=34\end{array}$ & BSG - 11 & HG - 13 & LG - 10 \\
\hline \multicolumn{5}{|l|}{ Characteristic } \\
\hline Age median & 10.4 years & 2.9 years & 3.8 years & 5.9 years \\
\hline Age range & $0.8-17.8$ years & $\begin{array}{c}2.7-12.25 \\
\text { years }\end{array}$ & $\begin{array}{c}3.3-17.8 \\
\text { years }\end{array}$ & 0.8 - 17.3 years \\
\hline Male & $13(35 \%)$ & 1 & 8 & 4 \\
\hline Female & $21(65 \%)$ & 10 & 5 & 6 \\
\hline Ethnicity & $\begin{array}{c}\text { W } 32(94 \%), \text { B } \\
1(3 \%), \text { M } 1 \\
(3 \%)\end{array}$ & W (100\%) & $\begin{array}{c}\text { W } 12(92 \%), \\
\text { B } 1(8 \%)\end{array}$ & $\begin{array}{c}\text { W } 9 \text { (90\%), M } 1 \\
(10 \%)\end{array}$ \\
\hline Median Karnofsky & 80 baseline/ 80 & 80 baseline $/ 80$ & 80 baseline $/ 70$ & 90 baseline/90 \\
\hline Performance Score & last evaluation & last evaluation & last evaluation & last evaluation \\
\hline \multicolumn{5}{|l|}{ Tumor Histology } \\
\hline DIPG & 9 & 9 & & \\
\hline $\begin{array}{l}\text { BSG/midbrain } \\
\text { (pilocytic } \\
\text { astrocytoma) }\end{array}$ & 2 & 2 & & \\
\hline GBM & 5 & & 5 & \\
\hline $\begin{array}{c}\text { Anaplastic } \\
\text { oligodendroglioma }\end{array}$ & 1 & & 1 & \\
\hline Gliosarcoma & 1 & & 1 & \\
\hline $\begin{array}{c}\text { Anaplastic } \\
\text { astrocytoma }\end{array}$ & 3 & & 3 & \\
\hline Anaplastic glioma & 1 & & 1 & \\
\hline $\begin{array}{c}\text { sPNET } \\
\text { (medulloepithelioma) }\end{array}$ & 1 & & 1 & \\
\hline $\begin{array}{c}\text { PNET } \\
\text { (medulloblastoma) }\end{array}$ & 1 & & 1 & \\
\hline Astrocytoma & 2 & & & 2 \\
\hline Pilocytic astrocytoma & 1 & & & 1 \\
\hline Craniopharyngioma & 1 & & & 1 \\
\hline Ganglioglioma & 2 & & & 2 \\
\hline $\begin{array}{c}\text { Ganglioma-desmoplas } \\
\text { tic infantile }\end{array}$ & 1 & & & 1 \\
\hline Neurocytoma & 1 & & & 1 \\
\hline Oligodendroglioma & 1 & & & 1 \\
\hline Optic pathway & 1 & & & 1 \\
\hline \multicolumn{5}{|l|}{ Prior treatment } \\
\hline None or biopsy only & 6 & 2 & 2 & 2 \\
\hline SU & 16 & 1 & 8 & 7 \\
\hline $\mathrm{SU}+\mathrm{CH}+\mathrm{RT}$ & 3 & 0 & 3 & 0 \\
\hline $\mathrm{CH}$ & 2 & 1 & 0 & 1 \\
\hline $\mathrm{CH}+\mathrm{RT}$ & 3 & 3 & 0 & 0 \\
\hline $\mathrm{RT}$ & 4 & 4 & 0 & 0 \\
\hline $\mathrm{SU}+\mathrm{RT}$ & 0 & 0 & 0 & 0 \\
\hline
\end{tabular}

Note. B-African-American, BSG-brainstem glioma, $\mathrm{CH}$-chemotherapy, DIPG-diffuse intrinsic pontine glioma, GBM-glioblastoma multiforme, HG-high-grade, LG-low-grade, M-Latin American, PNET-primitive neuroectodermal tumor, sPNET-supratentorial primitive neuroectodermal tumor, $\mathrm{SU}$-surgery, RT—radiation therapy, $\mathrm{W}-$ Caucasian. 
Table 2. Summary of Cases of Complete and Partial Response.

\begin{tabular}{|c|c|c|c|c|c|c|c|c|c|c|c|}
\hline \multirow{2}{*}{ Group } & \multirow{2}{*}{ Case } & \multirow{2}{*}{$\begin{array}{c}\text { Age } \\
\text { (years) }\end{array}$} & \multirow{2}{*}{ Tumor Type } & \multirow{2}{*}{$\begin{array}{l}\text { Past } \\
\text { SU }\end{array}$} & \multirow{2}{*}{$\begin{array}{l}\text { Past } \\
\mathrm{CH}\end{array}$} & \multirow{2}{*}{$\begin{array}{c}\text { Past } \\
\text { RT }\end{array}$} & \multicolumn{2}{|c|}{$\begin{array}{c}\text { Tumor cross-section } \\
\text { area }\left(\mathrm{cm}^{2}\right)\end{array}$} & \multirow{2}{*}{$\begin{array}{c}\text { Best Response } \\
\text { to Treatment }\end{array}$} & \multirow{2}{*}{$\begin{array}{c}\text { OS } \\
\text { (months) }\end{array}$} & \multirow{2}{*}{$\begin{array}{c}\text { PFS } \\
\text { (months) }\end{array}$} \\
\hline & & & & & & & Baseline & $\begin{array}{c}\text { Best } \\
\text { response }\end{array}$ & & & \\
\hline \multirow{3}{*}{$\begin{array}{l}\text { Brainstem } \\
\text { glioma }\end{array}$} & 19 & 2 & $\begin{array}{l}\text { Pilocytic } \\
\text { astrocytoma } \\
\text { /midbrain }\end{array}$ & Yes & No & No & 19.0 & resolved & CR & $94.2+$ & 19.0 \\
\hline & 24 & 4 & DIPG & No & No & Yes & 0.36 & resolved & CR & 14.2 & 14.2 \\
\hline & 26 & 6 & DIPG & No & No & Yes & 3.90 & resolved & PR & 8.7 & 8.5 \\
\hline \multirow{3}{*}{$\begin{array}{l}\text { Low-grade } \\
\text { glioma }\end{array}$} & 11 & 8 & $\begin{array}{l}\text { Ganglio- } \\
\text { Glioma } \\
(\mathrm{MC}, \mathrm{L})\end{array}$ & Yes & No & No & 4.56 & 1.08 & PR & $189.7+$ & $189.7+$ \\
\hline & 32 & 0.83 & $\begin{array}{c}\text { Ganglio- } \\
\text { glioma- } \\
\text { desmoplastic } \\
\text { infantile }\end{array}$ & Yes & No & No & 18.0 & 4.2 & PR & $36.6+$ & $36.6+$ \\
\hline & 34 & 9 & $\begin{array}{c}\text { Pilocytic } \\
\text { astrocytoma } \\
(\mathrm{MC}, \mathrm{D}, \mathrm{L})\end{array}$ & Yes & Yes & No & 4.33 & 1.26 & PR & $39.0+$ & 15.4 \\
\hline
\end{tabular}

Note. BSG-brainstem glioma, CH-chemotherapy, CR—complete response, D-disseminated, DIPG-diffuse intrinsic pontine glioma, L-leptomeningeal, MC-multicentric, NA-not applicable, OS-overall survival from start, PFS—progression-free survival, PR—partial response, SU—surgery, RT-radiation therapy. Tumor measurements were performed on T1 contrast images.

a CR and is currently alive, having survived 8 and 8 months at last contact. This patient did not receive any treatment before ANP (Figure 1). The other BSG patient failed chemotherapy, received ANP and developed PD. However, after discontinuation of ANP, the patient is alive, having survived over seven years.

In the group of patients with LG, one patient relapsed after two surgical resections, but then achieved a PR following treatment with ANP. This patient is alive, tumor-free, off all treatment, and surviving for more than 15 years at last contact. Two additional patients who relapsed after surgical resection (one patient after two resections) achieved a PR.

Objective response, PFS and OS data for all patients, for BSG, for high-grade tumors, and for low-grade tumors are shown in Table 3. Kaplan-Meier survival curves are shown in Figures 2-5.

The seven LG patients who did not obtain an OR are also alive. Among these surviving patients, there are cases of sPNET and neurocytoma which developed PD while on ANP treatment. After discontinuation of ANP, only one patient with a neurocytoma received chemotherapy. The patient diagnosed with oligodendroglioma is alive and surviving over 16 years at last contact despite maintaining only SD while receiving ANP. Table 4 presents the diagnosis, response to treatment, and OS survival data for the seven LG patients who did not achieve an OR while on ANP.

\subsection{Safety and Adverse Events}

Safety assessments were based upon the total number of enrolled patients in the study $(n=34)$. Intense, systematic monitoring of patient safety was conducted during the first two months of therapy and involved daily direct questioning 


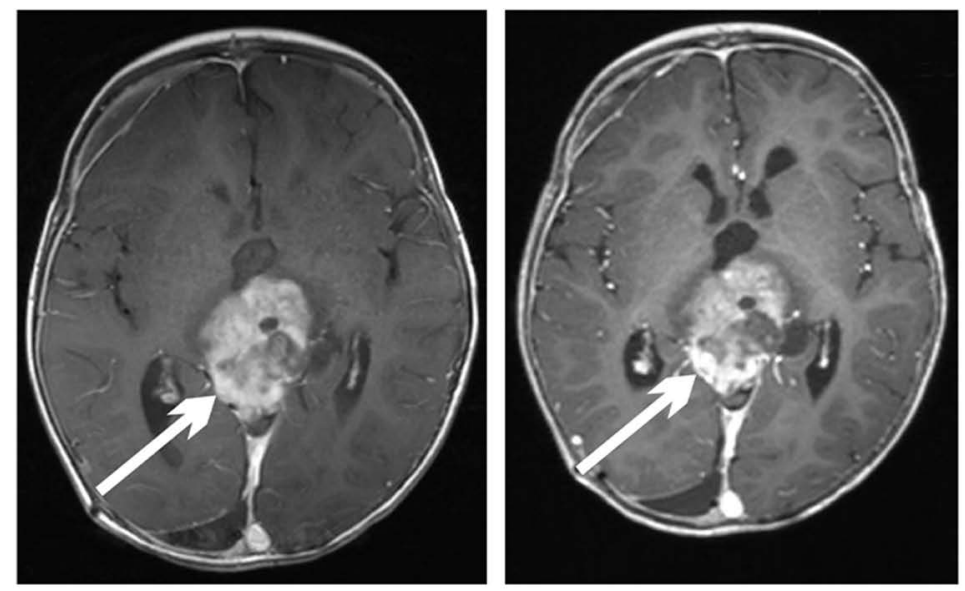

Baseline: March 24, 2008
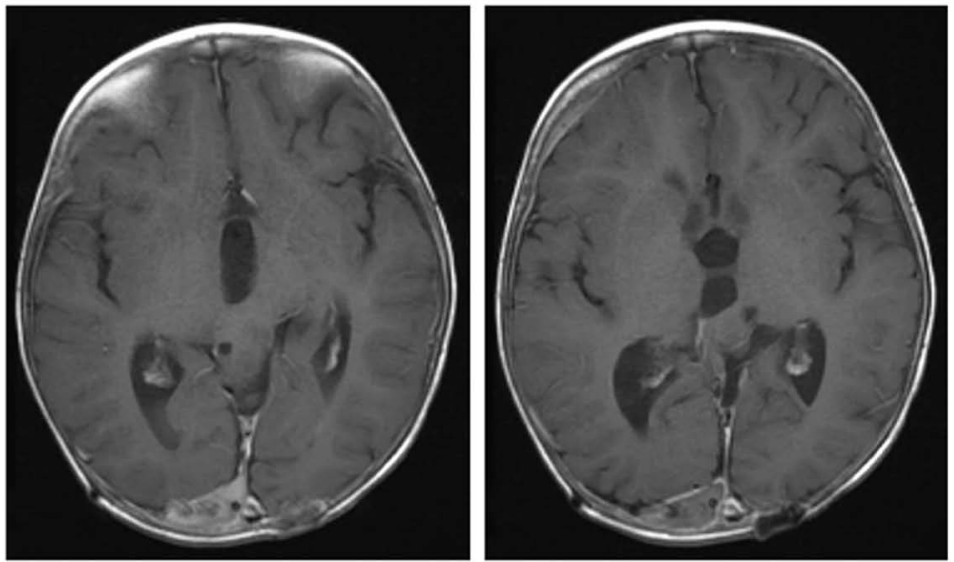

Follow-up: June 26, 2009

Figure 1. The top row shows images from a baseline MRI for a 3-year-old male child with a pilocytic astrocytoma of the brainstem, midbrain, which is delineated by arrows. The bottom row shows comparable images (axial T1, post-contrast images) from a subsequent MRI, which demonstrates complete resolution of the contrast-enhancing tumor.

Table 3. Survival Data.

\begin{tabular}{|c|c|c|c|c|c|c|c|c|c|c|c|}
\hline \multirow{3}{*}{$\begin{array}{l}\text { Tumor types } \\
\text { (N) }\end{array}$} & \multirow{3}{*}{ CR } & & & \multicolumn{2}{|c|}{$\begin{array}{l}\text { Progression-free } \\
\text { survival }\end{array}$} & \multicolumn{6}{|c|}{ Overall Survival from Treatment Start } \\
\hline & & $\mathrm{PR}$ & SD & Median & $\%$ at 6 & Median & 1 & 2 & 5 & 10 & 15 \\
\hline & & & & Months & months & months & year \% & years $\%$ & years \% & years $\%$ & years $\%$ \\
\hline $\begin{array}{l}\text { All Patients } \\
(34)\end{array}$ & 2 & 5 & 5 & 2.33 & 35.3 & 8.71 & 47.1 & 37.6 & 34.5 & 34.5 & 25.9 \\
\hline BSG (11) & 2 & 1 & 1 & 4.86 & 45.5 & 8.71 & 36.4 & 18.2 & 18.2 & NA & NA \\
\hline $\begin{array}{l}\text { High-grade } \\
\text { tumors (13) }\end{array}$ & 0 & 0 & 1 & 1.38 & 7.69 & 3.52 & 23.1 & 11.5 & 11.5 & 11.5 & 0 \\
\hline $\begin{array}{l}\text { Low-grade } \\
\text { tumors (10) }\end{array}$ & 0 & 4 & 3 & 6.57 & 60.0 & NA & 90.0 & 90.0 & 80.0 & 80.0 & 80.0 \\
\hline
\end{tabular}

Note. BSG-brainstem glioma, $\mathrm{CR}-$ complete response, $\mathrm{N}-$ number, $\mathrm{PR}-$ partial response, $\mathrm{SD}-$ stable disease.

concerning adverse events, first at the clinic and then followed by phone calls during the home administration. After two months, telephone contact was conducted on a weekly basis. Adverse events were coded and graded according to 


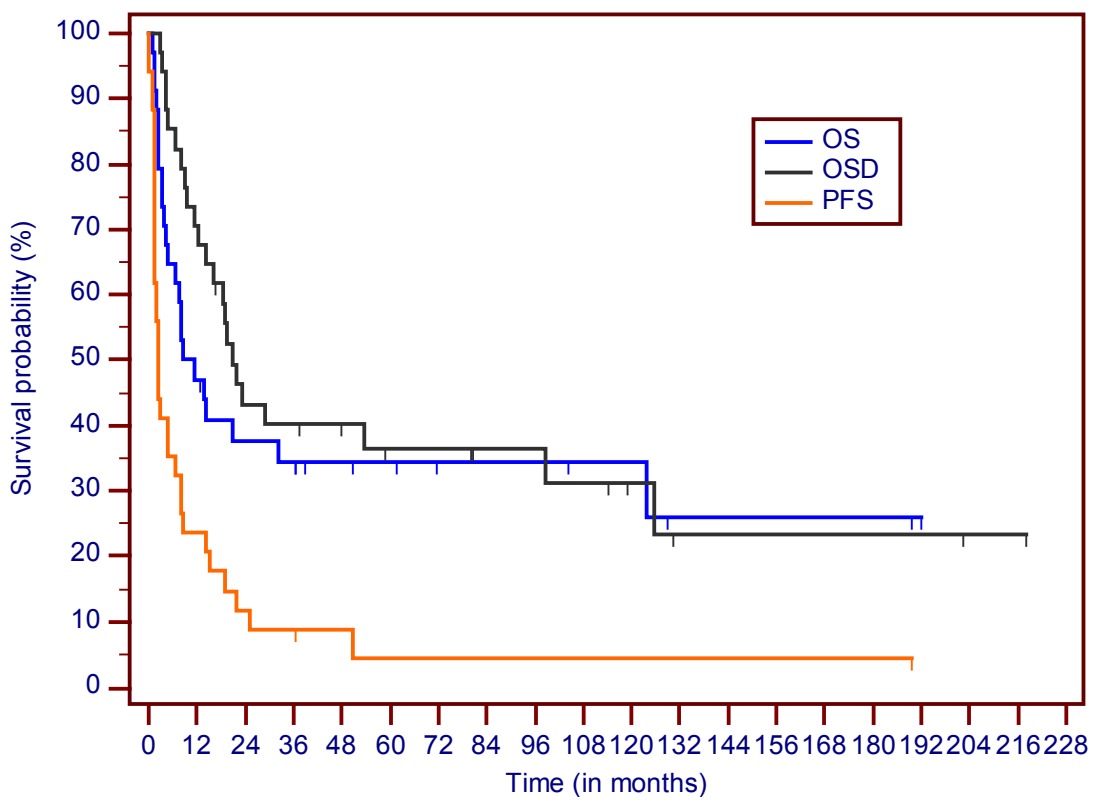

Figure 2. Kaplan-Meier survival curves (all patients). (Note. OSD-overall survival from diagnosis, OS-overall survival from treatment start, PFS-progression-free survival).

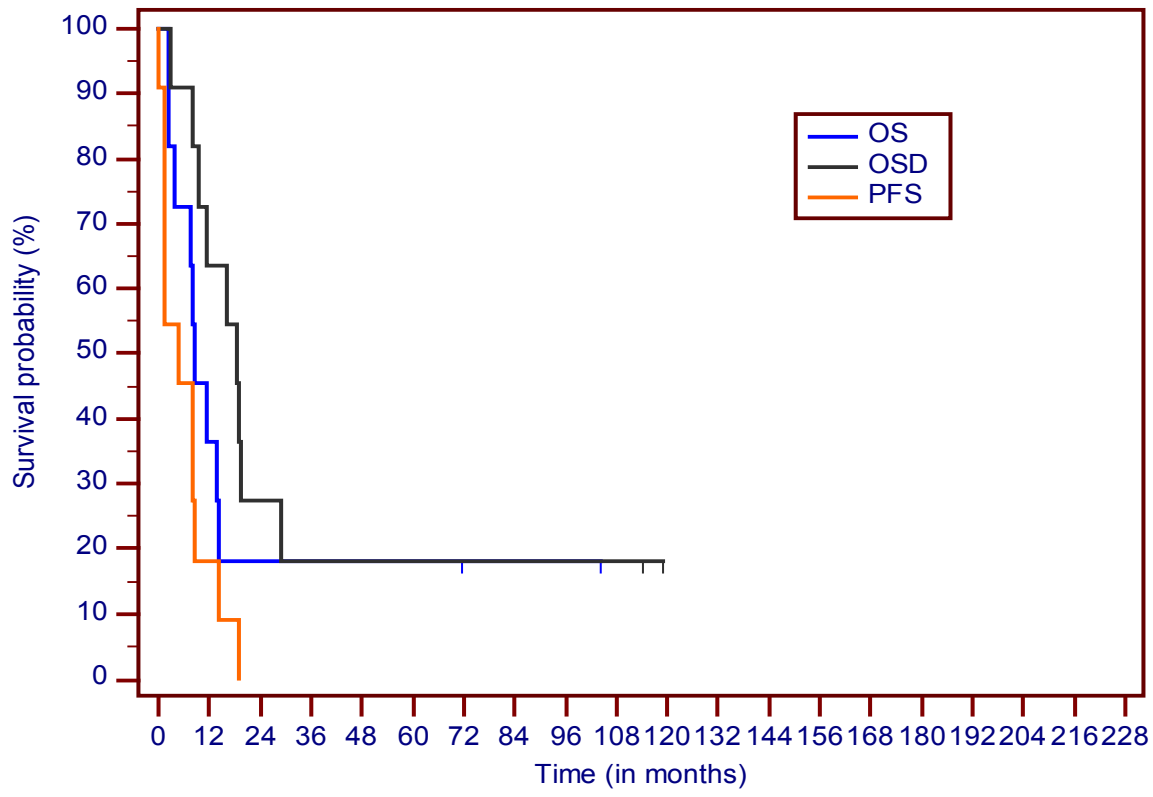

Figure 3. Kaplan-Meier survival curves (BSG group). (Note. OSD-overall survival from diagnosis, OS-overall survival from treatment start, PFS—progression-free survival).

Version 3.0 of the Common Terminology Criteria for Adverse Events (CTCAE v 3.0).

Adverse Drug Events (ADEs) included grade 4 hypernatremia (x2); grade 3 hypokalemia (x3); grade 1 headache $(\mathrm{x} 1)$, somnolence $(\mathrm{x} 1)$, anemia $(\mathrm{x} 1)$ and $\mathrm{fa}$ tigue (x1). No long-term ADE to ANP has been reported.

Brain tumor patients frequently receive corticosteroids to reduce cerebral edema around tumors. The use of corticosteroids and the infusion of large volumes of sodium-containing solutions during ANP therapy predispose patients 


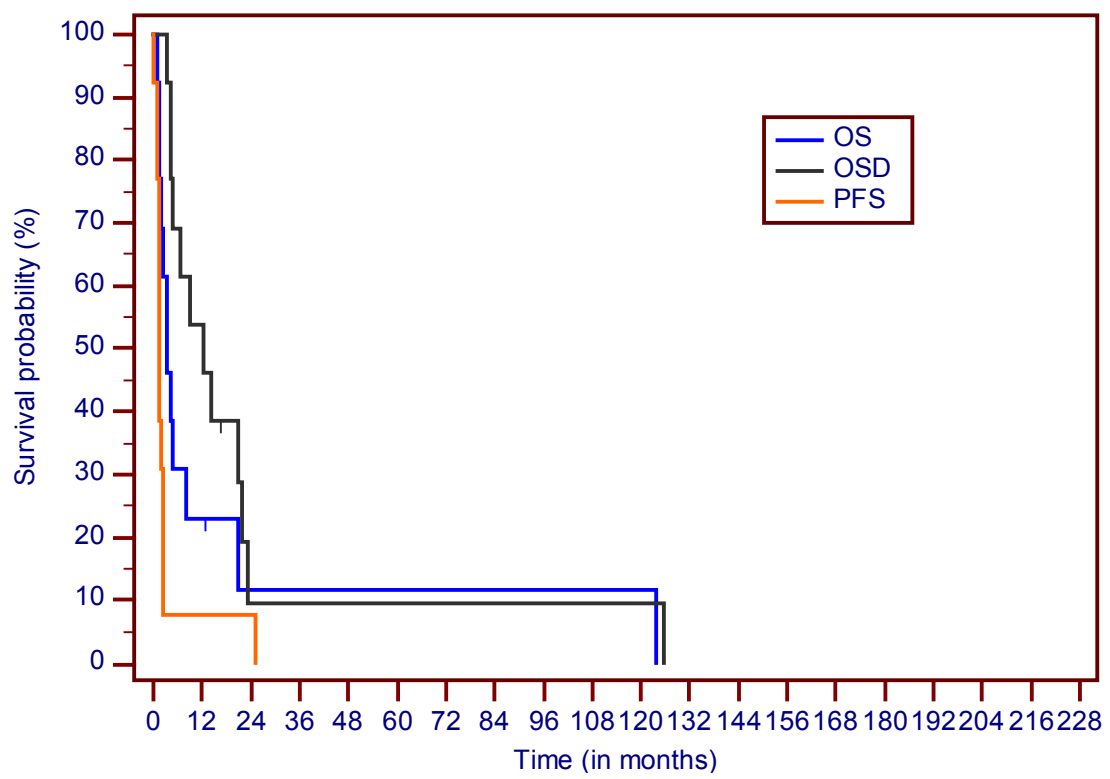

Figure 4. Kaplan-Meier survival curves (High-grade tumors group). (Note. OSD-overall survival from diagnosis, OS-overall survival from treatment start, PFS-progression-free survival).

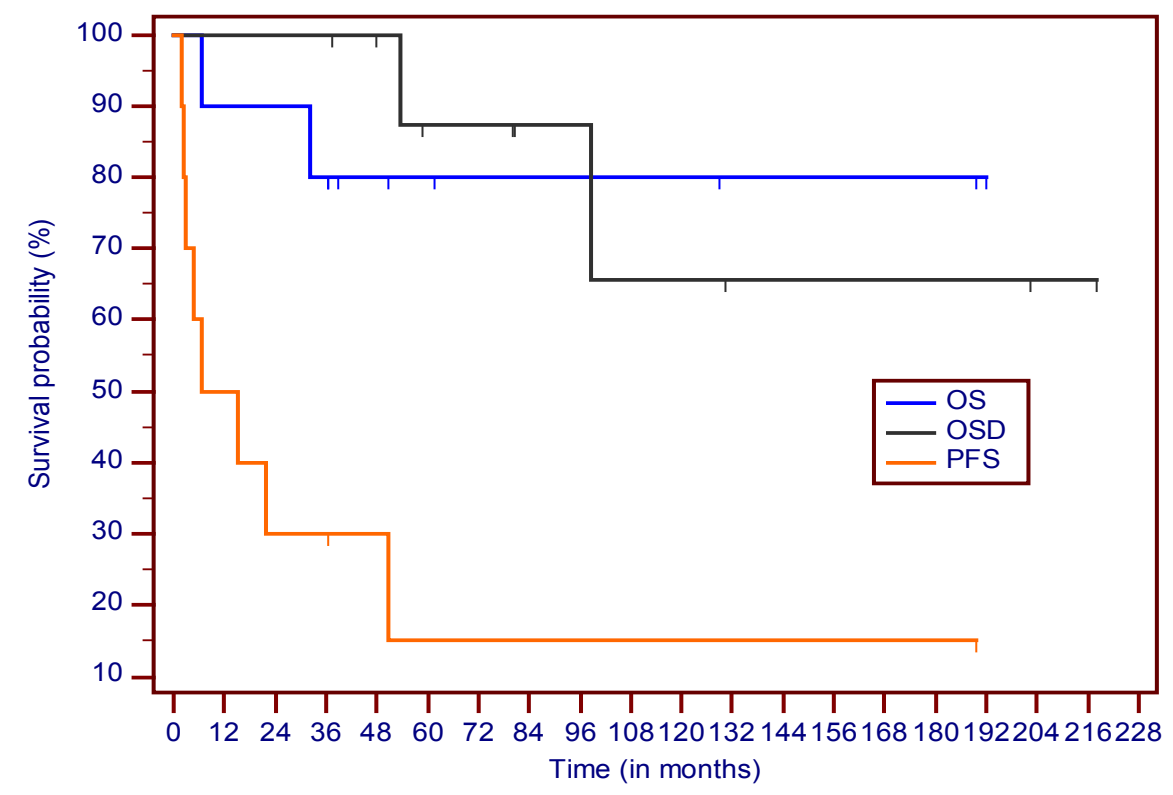

Figure 5. Kaplan-Meier survival curves (Low-grade tumors group). (Note. OSD-overall survival from diagnosis, OS-overall survival from treatment start, PFS—progression-free survival).

to serum sodium concentration abnormalities. Grade 4 reversible hypernatremia, possibly related to ANP was reported in 2 cases (5.8\%).

\section{Discussion}

The protocol study presented here included 34 patients with both high-grade and low-grade primary pediatric brain tumors. Twenty-four patients (70.6\%) suffered from a brainstem glioma (BSG) or high-grade tumor. Ten patients 
Table 4. Overall Survival for LG Patients not achieving an OR.

\begin{tabular}{ccccc}
\hline Group & Case & Diagnosis & $\begin{array}{c}\text { Response to } \\
\text { treatment }\end{array}$ & $\begin{array}{c}\text { Overall Survival } \\
\text { from Treatment } \\
\text { Start }\end{array}$ \\
\hline BSG & 25 & $\begin{array}{c}\text { Brainstem glioma, mid-brain, } \\
\text { pilocytic astrocytoma. }\end{array}$ & PD & $71.6+$ \\
HG & 13 & $\begin{array}{c}\text { Medulloepithelioma (sPNET). } \\
\text { Oligodendroglioma. }\end{array}$ & PD & $12.85 \mathrm{LF}$ \\
& 2 & SD & $192+$ \\
LG & 15 & Neurocytoma. & PD & $61.6 \mathrm{LF}$ \\
& 16 & $\begin{array}{c}\text { Mixed Glioma (Ependymoma and } \\
\text { Astrocytoma, grade II). } \\
\text { Ganglioglioma in the }\end{array}$ & PD & $36.5 \mathrm{LF}$ \\
& 31 & thalamo-mesencephalic of the brain. & SD & $129.1 \mathrm{LF}$ \\
\hline
\end{tabular}

Note. +-alive and counting, BSG-brainstem glioma, HG-high grade, LF-lost for follow-up, LGlow-grade, $\mathrm{NE}-$ not evaluable, $\mathrm{PD}-$ progressive disease, $\mathrm{SD}$-stable disease, $\mathrm{SPNET}$ - supratentorial primitive neuroectodermal tumor.

(29.4\%) suffered from a low-grade tumor.

Among ten BSG patients, three patients had newly diagnosed tumors while seven patients suffered from recurrent disease after standard therapy. Two of eight patients in the DIPG group achieved an OR (one PR, one CR), while another three patients maintained SD. One patient with a thalamic astrocytoma extending to the brainstem is currently free of disease nearly five years after the start of ANP. These data compare favorably to the published data of other studies [5] [19] [26] [27] [28] [29]. In most of these studies, very few, if any, ORs were observed while the OS for most patients was less than six months. A report of another completed study of ANP in BSG, conducted at the Burzynski Clinic with a larger patient population, is in preparation for publication.

The results in GGs were of interest. A ganglioglioma is composed of cells of both glial and neural origin and was originally described by Perkins in 1926 [30]. These tumors occur in all age groups, but are most common in the pediatric population [31]. Generally they behave in a benign manner, but a subset of these tumors, with a higher grade glial component, is more aggressive [32]. The treatment of choice is surgical resection, but only complete resection results in long-term, disease-free survival [33] [34]. GGs displaying malignant features may benefit from RT while the efficacy of chemotherapy is unknown [35].

Desmoplastic infantile ganglioglioma (DIG) is a very rare tumor and distinct from other GGs [36]. Histologically DIG has only rare mitoses and no necrosis or microvascular proliferation. It is expected that the occurrence of more frequent mitoses indicates a high-grade tumor [21]. Except for surgical resection, effective treatment for DIG is not known. The study reported here included three patients with GGs, one of which was a DIG. In two cases the tumors recurred after two resections and one patient had multicentric disease with thalamic location of the main tumor. This patient obtained a CR and was alive with a survival of over 13 years at last contact. The second patient achieved a PR on ANP. The third patient, diagnosed with DIG, developed recurrence after initial 
surgery and subsequently achieved a PR on ANP. The number of GG cases reported here is small but suggests a possible role for ANP in the treatment of GG, including DIG.

The treatment of primary pediatric brain tumors is challenging. In this report, we describe a Phase II study of ANP and present encouraging objective response and survival data in BSG and GG patients. Of special interest are the results in recurrent DIPG. An IRB-approved phase II study of ANP in DIPG and a pending phase III study will provide more definitive data regarding the efficacy and safety of ANP in DIPG.

\section{Acknowledgements}

The authors express their appreciation to all involved in the care of the patients, Drs. Robert A. Weaver, Robert I. Lewy, Eva Kubove, Barbara Szymkowski, and Mohammad Khan. Preparation of the manuscript was provided by Samuel Beenken, M.D. Jenifer Pineda and Ramiro Rivera, MD provided assistance in data review. Editorial assistance was provided by Samuel Beenken, M.D.

\section{References}

[1] Ostrom, Q.T., Gittleman, H., Xu, J., Kromer, C., Wolinsky, Y., Kruchko, C., et al. (2016) CBTRUS Statistical Report: Primary Brain and Other Central Nervous System Tumors Diagnosed in the United States in 2009-2013. Neuro-Oncology, 18, v1v75. https://doi.org/10.1093/neuonc/nov297

[2] Porter, K.R., McCarthy, B.J., Freels, S., Kim, Y. and Davis, F.G. (2010) Prevalence Estimates for Primary Brain Tumors in the United States by Age, Gender, Behavior and Histology. Neuro-Oncology, 12, 520-527. https://doi.org/10.1093/neuonc/nop066

[3] Komotar, R.J., Burger, P.C., Carson, B.S., Brem, H., Olivi, A., Goldthwaite, P.T., et al. (2004) Pilocytic and Pilomyxoid Hypothalamic/Chiasmatic Astrocytomas. Neurosurgery, 54, 72-80. https://doi.org/10.1227/01.neu.0000097266.89676.25

[4] Broniscer, A. and Gajjar, A. (2004) Supratentorial High-Grade Astrocytoma and Diffuse Brainstem Glioma: Two Challenges for the Pediatric Oncologist. Oncologist, 9, 197-206. https://doi.org/10.1634/theoncologist.9-2-197

[5] Burzynski, S.R. (2006) Treatments for Astrocytic Tumors in Children: Current and Emerging Strategies. Pediatric Drugs, 8, 167-168. https://doi.org/10.2165/00148581-200608030-00003

[6] Burzynski, S.R. (2004) The Present State of Antineoplaston Research (1). Integrative Cancer Therapies, 3, 47-58. https://doi.org/10.1177/1534735403261964

[7] Burzynski, S.R., Weaver, R.A., Janicki, T., Szymkowski, B., Jurida, G., Khan, M., et al. (2005) Long-Term Survival of High-Risk Pediatric Patients with Primitive Neuroectodermal Tumors Treated with Antineoplastons A10 and AS2-1. Integrative Cancer Therapies, 4, 168-177. https://doi.org/10.1177/1534735405276835

[8] Burzynski, S.R., Janicki, T.J., Burzynski, G.S. and Marszalek, A. (2014) A Phase II Study of Antineoplastons A10 and AS2-1 in Children with High-Grade Glioma. Final Report (Protocol BT-06) and Review of Recent Trials. Journal of Cancer Therapy, 5, 565-577. https://doi.org/10.4236/jct.2014.56065

[9] Burzynski, S.R., Janicki, T.J., Burzynski, G.S. and Marszalek, A. (2014) The Response and Survival of Children with Recurrent Diffuse Intrinsic Pontine Gliomas 
Based on Phase II Study of Antineoplastons A10 and AS2-1 in Patients with Brainstem Glioma. Child's Nervous System, 30, 2051. https://doi.org/10.1007/s00381-014-2401-Z

[10] Burzynski, S.R., Janicki, T.J., Burzynski, G.S. and Marszalek, A. (2015) A Phase II Study of Antineoplastons A10 and AS2-1 in Patients with Brainstem Gliomas. The Report on Non-Diffuse Intrinsic Pontine Glioma (Protocol BT-11). Journal of Cancer Therapy, 6, 334-344. https://doi.org/10.4236/jct.2015.64036

[11] Burzynski, S.R., Janicki, T.J. and Burzynski, G.S. (2016) A Phase II Study of Antineoplastons A10 and AS2-1 in Children with Low-Grade Astrocytomas-Final Report (Protocol BT-13). Journal of Cancer Therapy, 7, 837-850. https://doi.org/10.4236/jct.2016.712083

[12] Burzynski, S.R., Janicki, T.J., Burzynski, G.S., Marszalek, A. and Brookman, S. (2014) A Phase II Study of Antineoplastons A10 and AS2-1 in Children with Recurrent, Refractory or Progressive Primary Brain Tumors-Final Report (Protocol BT-22). Journal of Cancer Therapy, 5, 977-988. https://doi.org/10.4236/jct.2014.510102

[13] Burzynski, S.R., Janicki, T.J. and Burzynski, G.S. (2016) Primary CNS Tumors and Leptomeningeal, Disseminated and/or Multicentric Disease in Children Treated in Phase II Studies with Antineoplastons A10 and AS2-1. Cancer and Clinical Oncology, 5, 38-48. https://doi.org/10.5539/cco.v5n2p38

[14] Burzynski, S.R., Janicki, T.J., Burzynski, G.S. and Marszalek, A. (2014) Long-Term Survival (>13 Years) in a Child with Recurrent Diffuse Intrinsic Pontine Glioma: A Case Report. Journal of Pediatric Hematology/Oncology, 36, e433-e439. https://doi.org/10.1097/MPH.0000000000000020

[15] Burzynski, S.R., Burzynski, G.S., Janicki, T.J. and Marszalek, A. (2014/2015) Complete Response and Long-Term Survival (>20 Years) of a Child with Tectal Glioma: A Case Report. Pediatric Neurosurgery, 50, 99-103. https://doi.org/10.1159/000369907

[16] Burzynski, S.R., Burzynski, G.S., Marszalek, A., Janicki, T. and Martinez-Canca, J.F. (2015) Long-Term Survival over 21 Years and Pathologically Confirmed Complete Response in Pediatric Anaplastic Astrocytoma: A Case Report. Journal of Neurology \& Stroke, 2, Article No. 00072. https://doi.org/10.15406/jnsk.2015.02.00072

[17] Burzynski, S.R., Burzynski, G.S., Marszalek, A., Janicki, T. and Martinez-Canca, J.F. (2015) Long-Term Survival (over 20 Years), Complete Response and Normal Childhood Development in Medulloblastoma Treated with Antineoplastons A10 and AS2-1. Journal of Neurology \& Stroke, 2, Article No. 00054. https://doi.org/10.15406/jnsk.2015.02.00054

[18] Albright, A.L., Packer, R.J., Zimmerman, R., Rorke, L.B., Boyett, J. and Hammond, G.D. (1993) Magnetic Resonance Scans Should Replace Biopsies for the Diagnosis of Diffuse Brain Stem Gliomas: A Report from the Children's Cancer Group. Neurosurgery, 33, 1026-1030. https://doi.org/10.1227/00006123-199312000-00010

[19] Hargrave, D., Bartels, U. and Bouffet, E. (2006) Diffuse Brainstem Glioma in Children: Critical Review of Clinical Trials. The Lancet, 7, 241-248. https://doi.org/10.1016/S1470-2045(06)70615-5

[20] Packer, R.J., Boyett, J.M., Zimmerman, R.A., Rorke, L.B., Kaplan, A.M., Albright, A.L., et al. (1993) Hyperfractionated Radiation Therapy (72 Gy) for Children with Brain Stem Gliomas. A Children's Cancer Group Phase I/II Trial. Cancer, 72, 1414 1421.

https://doi.org/10.1002/1097-0142(19930815)72:4<1414::AID-CNCR2820720442>3. $\underline{0 . \mathrm{CO} ; 2-\mathrm{C}}$ 
[21] Wen, P.Y., Macdonald, D.R., Reardon, D.A., Cloughesy, T.F., Sorensen, A.G., Galanis, E, et al. (2010) Updated Response Assessment Criteria for High-Grade Gliomas: Response Assessment in Neuro-Oncology Working Group. Journal of Clinical Oncology, 28, 1963-1972. https://doi.org/10.1200/JCO.2009.26.3541

[22] Choux, M., Lena, G. and Do, L. (2000) Brainstem Tumors. In: Choux, M., Di Rocco, C. and Hockley, A., Eds., Pediatric Neurosurgery, Churchill Livingstone, New York, 471-491.

[23] Leach, P.A., Estlin, E.J., Coope, D.J., Thorne, J.A. and Kamaly-Asl, I.D. (2008) Diffuse Brainstem Gliomas in Children: Should We or Shouldn't We Biopsy? British Journal of Neurosurgery, 22, 619-624. https://doi.org/10.1080/02688690802366198

[24] Chang, S.M., Kuhn, J.G., Robins, H.I., Schold, S.C., Spence, A.M., Berger, M.S., et al. (1999) Phase II Study of Phenylacetate in Patients with Recurrent Malignant Glioma: A North American Brain Tumor Consortium Report. Journal of Clinical Oncology, 17, 984-990.

[25] Weller, M., Cloughesy, T., Perry, J.R. and Wisk, W. (2013) Standards of Care for Treatment of Recurrent Glioblastoma-Are We There Yet? Neuro-Oncology, 15, 427. https://doi.org/10.1093/neuonc/nos273

[26] Fouladi, M., Nicholson, H.S., Zhou, T., Laningham, F., Helton, K.J., Holmes, E., et al. (2007) A Phase II Study of the Farnesyl Transferase Inhibitor, Tipifarnib, in Children with Recurrent or Progressive High-Grade Glioma, Medulloblastoma/Primitive Neuroectodermal Tumor, or Brainstem Glioma: A Children's Oncology Group study. Cancer, 110, 2535-2541. https://doi.org/10.1002/cncr.23078

[27] Gururangan, S., Chi, S.N., Young Poussaint, T., Onar-Thomas, A., Gilbertson, R.J., Vajapeyam, S., et al. (2010) Lack of Efficacy of Bevacizumab Plus Irinotecan in Children with Recurrent Malignant Glioma and Diffuse Brainstem Glioma: A Pediatric Brain Tumor Consortium Study. Journal of Clinical Oncology, 28, 30693075. https://doi.org/10.1200/JCO.2009.26.8789

[28] Lashford, L.S., Thiesse, P., Jouvet, A., Jaspan, T., Couanet, D., Griffiths, P.D., et al. (2002) Temozolomide in Malignant Gliomas of Childhood: A United Kingdom Children's Cancer Study Group and French Society for Pediatric Oncology Intergroup Study. Journal of Clinical Oncology, 20, 4684-4691. https://doi.org/10.1200/JCO.2002.08.141

[29] Warren, K.E., Gururangan, S., Geyer, J.R., McLendon, R.E., Poussaint, T.Y., Wallace, D., et al. (2012) A Phase II Study of 06-benzylguanine and Temozolomide in Pediatric Patients with Recurrent or Progressive High-Grade Gliomas and Brainstem Gliomas: A Pediatric Brain Tumor Consortium study. Journal of Neurooncology, 106, 643-649. https://doi.org/10.1007/s11060-011-0709-z

[30] Perkins, O.C. (1926) Gangliogliomas. Archives of Pathology \& Laboratory Medicine, 2, 11-17.

[31] Luyken, C., Blumcke, I., Fimmers, R., Urbach, H., Wiestler, O.D. and Schramm, J. (2004) Supratentorial Gangliogliomas: Histopathologic Grading and Tumor Recurrence in 184 Patients with a Median Follow-Up of 8 Years. Cancer, 101, 146-155. https://doi.org/10.1002/cncr.20332

[32] Matsuzaki, K., Uno, M., Kageji, T., Hirose, T. and Nagahiro, S. (2005) Anaplastic Ganglioglioma of the Cerebellopontine Angle. Case Report. Neurologia Medico-Chirurgica, 45, 591-595. https://doi.org/10.2176/nmc.45.591

[33] Matsumoto, K., Tamiya, T., Ono, Y., Furuta, T., Asari, S. and Ohmoto, T. (1999) Cerebral Gangliogliomas: Clinical Characteristics, CT and MRI. Acta Neurochirurgica, 141, 135-141. https://doi.org/10.1007/s007010050277

[34] Rumana, C.S., Valadka, A.B. and Contant, C.R. (1999) Prognostic Factors in Supra- 
tentorial Ganglioglioma. Acta Neurochirurgica, 141, 63-68.

[35] Liauw, S.L., Byer, J.E., Yachnis, A.T., Amdur, R.J. and Mendenhall, W.M. (2007) Radiotherapy after Subtotally Resected or Recurrent Ganglioglioma. International Journal of Radiation Oncology Biology Physics, 67, 244-247.

https://doi.org/10.1016/j.ijrobp.2006.08.029

[36] Pommepuy, I., Delage-Corre, M., Moreau, J.J. and Labrousse, F. (2006) A Report of a Desmoplastic Ganglioglioma in a 12 -Year-Old Girl with Review of the Literature. Journal of Neurooncology, 76, 271-275. https://doi.org/10.1007/s11060-005-6500-2

Submit or recommend next manuscript to SCIRP and we will provide best service for you:

Accepting pre-submission inquiries through Email, Facebook, LinkedIn, Twitter, etc. A wide selection of journals (inclusive of 9 subjects, more than 200 journals)

Providing 24-hour high-quality service

User-friendly online submission system

Fair and swift peer-review system

Efficient typesetting and proofreading procedure

Display of the result of downloads and visits, as well as the number of cited articles Maximum dissemination of your research work

Submit your manuscript at: http://papersubmission.scirp.org/

Or contact jct@scirp.org 